Librarian: career development, 2 (4), 1994, 29-31 [ISSN 0968-0810] [online]: http://www. emeraldinsight. com/Insight/viewPDF. jsp?Filename=html/Output/Published /EmeraldFullTextArticle/Pdf/1020020407.pdf [Accessed 26 June 2008]

\title{
S/NVQS AND HIGHER EDUCATION IN LIBRARIANSHIP AND INFORMATION STUDIES.
}

Ian M. Johnson, Head, School of Librarianship and Information Studies, The Robert Gordon University, Aberdeen

The development of National Vocational Qualifications (and Scottish Vocational Qualifications) has been generally welcomed by those employers who were concerned about the level of skills in the British workforce, and saw a move to improving skills training as a means of ensuring that Britain remained competitive in an increasingly global economy. It was clear that the amount of training undertaken by workers in many of our competitor countries was significantly greater than undertaken by comparable workers in Britain. The model chosen, competence-based education and training, is one which is currently attracting attention in other countries, including for example Australia. This short paper is intended to examine the implications of S/NVQs for the University Schools of Librarianship and Information Studies.

\section{!" A lasting effect?!}

Competence-based education and training originated in the United States in the $1960^{\prime} \mathrm{s}$. It is based on close analysis of the work undertaken by workers at all levels in an industry, identifying the range of tasks and suggesting the level of employee by whom the task should normally be undertaken. Analyses such as these were in fact undertaken in librarianship and information work in the U.S.A. in the 1970s, on a statewide basis in Illinois, and nationally using School Librarians as a discrete occupational sub-group. Enquiries in the early 1980 's suggested that these efforts had not been followed up in course design to any substantial extent by trainers or educators, except where such an analysis was a requirement of state education authorities for technician level courses similar to the U.K. City and Guilds Library Assistants Certificate. A few employers were using the analyses as a basis for developing job descriptions. Will the S/NVQs for Levels 1 to 4 currently being developed by the Information and Library Services Lead Body in the U.K. suffer a similar fate?

Experience to date is not encouraging, as training budgets in the information and library sector have generally received little priority in the allocation of funds. Some interesting indicators are also provided by developments in other sectors. Some large employers in the retail sector have already withdrawn from involvement with S/NVQS because the training is too broad for 
their requirements, and the cost and effort of delivery is not producing specific benefits. Small companies in the publishing sector have declined to enter the Publishing Industry Vocational Qualifications (PVQ) scheme because of its implications for staff time and other costs. There is, in some quarters, a healthy

Öґ: F7「 Šskepticism about whether the employers in the information and

library sector will find the will or the resources to develop and deliver the training necessary to establish a substantial programme of S/NVQS.

It might be feared that the quality of training for S/NVQs could prove to be as uneven as that of many library training programmes, because they may not be subject to the same quality assurance that exists in the University system. The process of regular validation and revalidation of those organisations accredited to offer S/NVQs on behalf of the awarding bodies should ensure that their approach remains reasonably satisfactory. However, the costs and the process of validation may deter many employers, particularly those who employ few specialists in librarianship and information work. This may, however, lead to third parties becoming validated to act as assessors. Some of these agents will be freelance consultants; others may be University Schools of Librarianship and Information Studies.

"! Implications for the LIS Schools!"

In the United States, the competence movement stemmed from the desperate need for trained manpower which afflicted almost every professional field in the Sixties. As they did during a similar shortage of personnel in the Second World War, the Americans turned to a utilitarian approach, attempting to introduce mass production techniques into education. Teacher education was the focus for the development of competence based education, but few traces of that approach appear to have survived. In the University Schools of Librarianship and Information Studies in the U.S.A., it made no impact. What then are the prospects for S/NVQS in the LIS Schools in the U.K.?

The Schools of Librarianship and Information Studies in the U.K. have generally taken a benign attitude to the development of Level 1-4 S/NVQs, seeing them principally as a means by which employers could improve the quality of their staff training, particularly for the large group of the library workforce which had not enjoyed access to the technician level courses validated by the City and Guilds Institute and by BTEC and SCOTVEC. The development of S/NVQs does, however, appear to pose some new questions for the University Schools of Librarianship and Information Studies.

Some, at least, of the Schools already recognise the existing technician level qualifications in the field (the City and Guilds Certificate, and the BTEC and SCOTVEC National Certificates) as alternatives to 'A' Levels and 'Highers', making their holders eligible to apply for admission undergraduate courses in 
Librarianship and Information Studies. The SCOTVEC Higher National Certificates are also seen as possible routes to direct entry into the second or third year of undergraduate courses. It seems likely that library staff with a substantial portfolio of relevant S/NVQs would be accorded similar treatment, i.e. they will be eligible to apply for admission. They will be subject to the same selection process as all other applicants, but their Öг: F7「 Šexperience and commitment will perhaps be given greater recognition than that of other applicants.

Another obvious issue is whether S/NVQs will become part of University courses. S/NVQs usually require some form of assessment in the workplace, and for most conventional University education that is impracticable. The number and nature of the assessments also present serious problems. Those Scottish University courses which are already teaching competence based SCOTVEC Higher National Diploma programmes are finding that the assessment load is too great for both staff and students, and that there are real difficulties in articulating into a parallel degree programme those students who have been assessed for two years on the basis of competence to perform tasks rather than on the basis of evidence of the development of their intellectual skills.

There are, however, two scenarios in which competence based assessment might be practicable and acceptable. Assessment of experiential learning is slowly acquiring a degree of acceptance in the Universities, either as prior experience which can be awarded academic credit, or as part of practical placements, usually subject to some form of learning contract. Both these options represent considerable additional work for Universities. Even the assessment of credits offered for transfer from other academic institutions can be quite a complex task. It is certainly time consuming if done properly, and always involves an element of compromise, leaving employers without the assurance that everyone graduating from a course has the same body of knowledge. Assessing prior experiential learning is probably more time-consuming and entails a greater element of compromise.

On the other hand, the development of learning contracts for practical placements, whilst initially demanding for the University and also presenting challenges for the employers who host students for placements, seems likely to produce results more easily capable of assessment and integration into the University programme. Those employers who already provide good placements will probably only find the initial negotiation of the contract to be more time-consuming; those who enter too lightly into their present commitments about placement programmes may find they need to review their approach. That may, however, benefit the development of training in their organisation.

Another question is whether S/NVQs will even be seen as an alternative to University education? This seems unlikely - for a number of reasons. Firstly, the issues of time and cost which have already been identified as an issue for the Universities will bear no less heavily on employers. Secondly, the University 
degree still has a social cachet which is unlikely to disappear in the foreseeable future. Thirdly, the main professional body in the U.K., the Library Association, went through considerable pains some years ago to establish information and library work as an all graduate profession. It will probably find it politically difficult to back away from graduate status, unless it is also abandoned by almost every other profession.

The question also has to be asked as to whether S/NVQs can Öг: F7「 Šdeliver what the University system aims to achieve, and what employers are primarily seeking from graduates in librarianship and information studies. The role of a professional information specialist is to identify and analyse user needs, design solutions, and manage their implementation. Implementation is the role of the technical and clerical staff, for whom competence based education may be appropriate. On the other hand, the essence of University education is to develop the student's ability to critically analyse and evaluate, and to develop problem solving abilities. The competence based S/NVQs at Level 1 to 4 do not make any attempt at this incremental, intellectual development. It is also part of a University education in Librarianship and Information Studies to develop the student's professional moral and ethical values. Whether it will be possible to develop the required intellectual skills and moral values through S/NVQ Level 5 alone remains open to question. Without these intellectual skills and values, will the products of the S/NVQ system be welcomed by employers as professional?

\section{!! Post qualification training!!}

It does not seem unrealistic to accept that the accumulation of S/NVQs may come to be seen as another alternate to the existing routes for graduates (in any discipline) who wish to become Chartered Librarians. However, the pursuit of S/NVQs is likely to be a long and arduous route, with many trainees failing to complete the programme, as was the case with the Association's Licentiateship scheme.

The very nature of S/NVQs may nonetheless focus attention on the need for regular staff development. No University lecturer in librarianship and information studies would deny the incipient redundancy of factual knowledge derived from their course. University courses are, therefore, revised annually, and students emerge with an understanding of the latest tools and techniques. However, those students who graduated a few years ago may have a body of out of date knowledge, particularly in areas of specialisation which they do not practice frequently, and may need to participate in refresher courses. The same is likely to be true of holders of S/NVQs; their knowledge base will also have a limited shelf life. They will not, however, stand in the same position as University graduates whose degree provides a lasting recognition of their intellectual powers and application, and S/NVQ holders may need to take refresher courses to maintain their certification. 
It is therefore likely that S/NVQs will have a role in continuing professional development (CPD), and some of this will be provided by the University Schools of Librarianship and Information Studies. Universities have already recognised that the award of a S/NVQ on completion of a CPD course may prove to be a good selling point. Under present tax arrangements, only courses leading to recognised qualifications such as S/NVQs are an allowable expense for individuals.

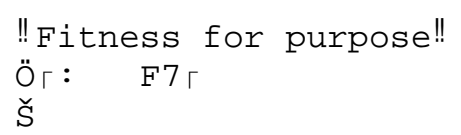

The Information and Library Studies Lead Body is only in the early stages of developing its framework for Level 5, which is regarded as the professional level. Perhaps significantly, few representatives of the Schools of Librarianship and Information Studies appear to have been involved in the consultation process at this level, removing from it a considerable accumulation of expertise in the analysis of the profession's manpower requirements. Whilst this may be (charitably) interpreted as a sign that the Lead Body sees its work as having little relevance to the Universities (or less charitably that it is excluding its perceived competitors), it is a matter for regret. The Schools and the employers should not be kept apart in a dialogue about the knowledge base and intellectual and personal skills which are required in a rapidly changing and diversifying environment.

\section{August 1994}

From: $\quad$ TOM WILSON <T.D.Wilson@sheffield.ac.uk>

To: plw@aber.ac.uk, r.alston@ucl.ac.uk, joan.day@unn.ac.uk, j.elkin@uk.ac.uce.ac.uk, i.m.johnson@RGU.AC.UK, A.Mills@lmu.ac.uk, pgbe@brighton.ac.uk, maburke@irlearn.ucd.ie, ser@is.city.ac.uk, m.evans1@lut.ac.uk, a.j.wood@mmu.ac.uk, charles@uk.ac.strathclyde.dis, A.Davies@queens-belfast.ac.uk, kate@la-hq.org.uk

Date sent:

Subject:

Priority:
Fri, 21 Apr 1995 11:06:31 +0100

normal
Euclid consultancy on NVQs 
I've been approached by one Juliet Herzog of a consultancy called Euclid for an interview on "whether or not there really is a demand for NVQs/SVQs at Level 5" (I quote from her fax) I've arranged to meet her on 26th May.

Has anyone else been approached?

My line will be the one we discussed at the last HoDS meeting that the task-specific nature of NVQs gives them no role in professional preparation. Any problems with this?

In fact, I'm working on a short paper that takes a rather harder line Öг: $\quad F 7\ulcorner$

Š- in a purely personal capacity, not as HoDS Chair. This is what it looks like to date:

NVQS: a framework for a former age?

T.D. Wilson

The Lead Body for NVQS in librarianship and information work recently sought opinions on the development of Level 5 NVQs, and suggested that the debate might be extended to the pages of the Record. This brief paper is intended as

a

contribution to that debate.

It will have escaped no one's attention that the NVQ framework is highly structured:

the patterns of work in an industry are 'mapped' and each function is defined in terms of the competencies needed to perform that function. Training programmes are then designed to deliver those competencies so that an organization may benefit from the availability of trained workers. Let there be no mistake the benefits are for the organization, the worker is a cog in the machine, ground to fit

the other cogs to interact more effectively (at least from the point-of-view of the organization). In essence, therefore, the scheme is anti-humanistic, mechanistic,

Taylorism made manifest. The needs of the individual, other than the need to find a niche in an economic system, have no place. The individual's needs as a human being in a social organization, are ignored.

Let us assume, however, that this is the way of the world: that this is what organizations need and, therefore, that we must accept the relevance of NVQs as a basis for training. But is it? What is the model of organizational work that underlies NVQs? It is, of course, essentially that of the 19th century factory, with

its then novel idea of the division of labour in keeping with the ideas of Adam Smith. In other words, Mrs. Thatcher's return to "Victorian values" in the workplace! Let us not forget that, whatever their electoral rhetoric, John Major

and his cabinet colleagues are Thatcherite to the core and that NVQs are part of 
this Government's inhumane and anti-social programme to diminish the value of people at work - and not only in money terms, so that we can be a European country with Third World wage levels, but also in terms of their self-worth and self-esteem.

What appears to have escaped the Government, the DTI, the Department of Employment, Lead Bodies, employers associations and professional bodies is that we are living in the final decade of the 20th century, not in the early decades of the

19 th.

Any programme for the prepartion of workers in any organization, as we enter the 21st century, must take account of some differences between the 19th century and the present:

* First, less work than ever before has a 'factory' structure: factory work which necessitated the division of labour for efficient production is increasingly automated and, indeed, roboticized. Graphic illustration of this was given recently in an announcement for a multi-million pound expansion of the Ford plant at Dagenham which would, however, generate no new jobs.

* Secondly, the majority of work today is information work. Leaving aside arguments about its definition and its consequent extent, there can be no doubt that, under any definition, the information sector is the biggest

Öг: $\quad F 7$ г

Šsector in Western, developed economies.

* Thirdly, within the information sector, and increasingly in the traditional

sectors, information technology is the main tool and the function of that tool is to integrate the previously divided tasks in many areas of work hence business process re-engineering or re-design, which has had a significant impact on the insurance industry (entirely an information industry). In insurance, previously sub-divided tasks that required days to process an application for an insurance policy, have been brought together through the technology in such a way that a case officer can process an application on screen in minutes. What has happened to the division of labour? It is irrelevant in this new workplace.

Thus, in NVQS we have a system based on an outmoded model of work, which takes no account of the integrative capabilities of information technology and which, for

these reasons alone - assuming we wish to ignore the intentionally dehumanising basis of the idea - is irrelevant to the needs of modern organizations.

This would be bad enough if NVQs were restricted to levels 1,2 and $3 \ldots$

NVQs mention the need for controlling and supervisory skills, but there is no mention

of the need for imagination, creativity, innovation - these are the true competencies of the information worker...

Is an NVQ level 4 or 5 really appropriate for the kind of world that, say, university

libraries are moving into when the Follett/FIGIT developments come to fruition?... 
Training for now is training for redundancy. Education is for the future.

Note: this short paper represents my personal views as a member of the Library Association. It should not be taken as representing the views of the University of

Sheffield, nor of the Department of Information Studies in that University, nor of

the Heads of Departments and Schools Committee of BAILER.

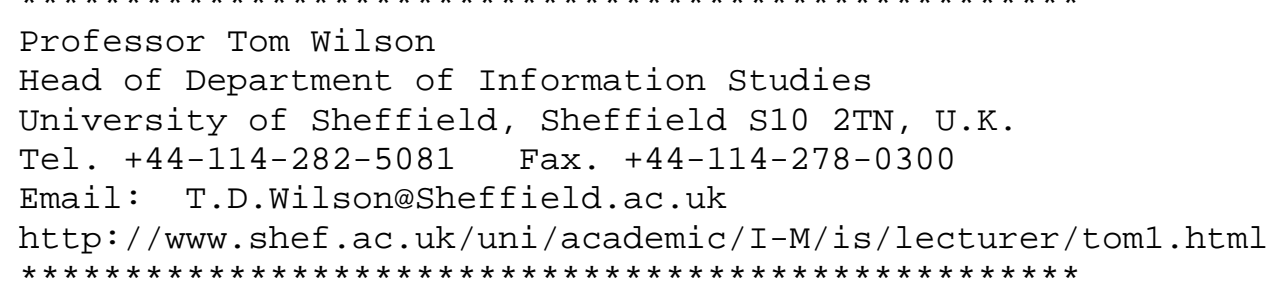

NVQs: a framework for a former age?

T.D. Wilson

The Lead Body for NVQS in librarianship and information work recently sought opinions on the development of Level 5 NVQS, and suggested that the debate might be extended to the pages of the Record. This brief paper is intended as a contribution to that debate.

$\ddot{O}\ulcorner: \quad \mathrm{F} 7\ulcorner$

ŠIt will have escaped no one's attention that the NVQ framework is highly structured: the patterns of work in an industry are 'mapped' and each function is defined in terms of the competencies needed to perform that function. Training programmes are then designed to deliver those competencies so that an organization may benefit from the availability of trained workers. Let there be no mistake - the benefits are for the organization, the worker is a cog in the machine, ground to fit the other cogs to interact more effectively (at least from the point-of-view of the organization). In essence, therefore, the scheme is anti-humanistic, mechanistic, Taylorism made manifest. The needs of the individual, other than the need to find a niche in an economic system, have no place. The individual's needs as a human being in a social organization, are ignored.

Let us assume, however, that this is the way of the world: that this is what organizations need and, therefore, that we must accept the relevance of NVQs as a basis for training. But is it? What is the model of organizational work that underlies NVQs? It is, of course, essentially that of the 19th century factory, with its then novel idea of the division of labour in keeping with the ideas of Adam Smith. In other words, Mrs. Thatcher's return to "Victorian 
values" in the workplace! Let us not forget that, whatever their electoral rhetoric, John Major and his cabinet colleagues are Thatcherite to the core and that NVQs are part of this Government's inhumane and anti-social programme to diminish the value of people at work - and not only in money terms, so that we can be a European country with Third World wage levels, but also in terms of their self-worth and self-esteem.

What appears to have escaped the Government, the DTI, the Department of Employment, Lead Bodies, employers associations and professional bodies is that we are living in the final decade of the 20th century, not in the early decades of the 19th.

Any programme for the prepartion of workers in any organization, as we enter the 21st century, must take account of some differences between the 19th century and the present:

\{SYMBOL $183 \backslash f$ "Symbol" \s $10 \backslash \mathrm{h}\}$ First, less work than ever before has a 'factory' structure: factory work which necessitated the division of labour for efficient production is increasingly automated and, indeed, roboticized.

Graphic illustration of this was given recently in an announcement for a multimillion pound expansion of the Ford plant at Dagenham which would, however, generate no new jobs.

\{SYMBOL $183 \backslash f$ "Symbol" Is $10 \backslash \mathrm{h}\}$ Secondly, the majority of work today is information work. Leaving aside arguments about its definition and its consequent extent, there can be no doubt that, under any definition, the information sector is the biggest sector in Western, developed economies.

\{SYMBOL 183 \f "Symbol" Is $10 \backslash \mathrm{h}$ \} Thirdly, within the information sector, and increasingly in the traditional sectors, information technology is the main tool and the function of that tool is to integrate the previously divided tasks in many areas of work - hence business process re-engineering or re-design, which has had a significant impact on the insurance industry (entirely an information industry). In insurance, previously sub-divided tasks that required days to process an application for an insurance policy, have been brought together through the technology in such a way that a case officer can process an application on screen in minutes. What has happened to the division of labour? It is irrelevant in this new workplace.

Thus, in NVQs we have a system based on an outmoded model of work, which takes no account of the integrative capabilities of information technology and which, for these reasons alone - assuming we wish to ignore the intentionally dehumanising basis of the idea - is irrelevant to the needs of modern organizations.

This would be bad enough if NVQs were restricted to levels 1,2 and 3 , but we are now faced with the prospect of seeing these qualifications introduced at the level of professional education. Let us imagine the possible scenario: graduates leaving university will find jobs in the library and information sector, they will then follow NVQs levels 4 and 5 and receive training in the performance of a range of functions. Necessarily, that training and those functions must be related to the way things are done in their parent organizations - they must be workplace-specific to satisfy the needs of the employers who, by funding the whole business, control the process and the output. What then, is the prospect for job mobility and personal career development? Will the Library Association accept NVQs as a basis for the Associateship? It has not yet decided but, as its Council is composed primarily of those who will 
be employing the trainees, we can assume that, in the end, it will. Where then will it find itself vis-á-vis other professional bodies, most of which appear to be very wary of wholeheartedly embracing NVQs? of course, the diminution of the power of professional bodies is also part of this Government's overall agenda - anything that limits the power of employers to find least-cost solutions to delivering products or services is to be removed if possible, or made powerless if not. Does the Association wish to be part of that agenda?

No doubt some will argue that a competency-based approach to professional development must include managerial skills and it is true that the recent Lead Body document on Level 5 NVQs mentions the need for controlling and supervisory skills. However, there is no mention of the need for imagination, creativity, innovation, analytical thought - these are the true competencies of the manager in any kind of organization and they are essential for modern librarians and information managers who, working in a turbulent environment with rapidly changing technologies, are faced every day with decisions that demand these qualities. NVQs at levels 4 and 5 will not deliver those capabilities.

Consider the future of university libraries as envisaged in the Follett report and as it is expected to emerge out of the projects to be supported under the FIGIT programme. Is an NVQ level 4 or 5 really appropriate for the kind of world that, evisages electronic document delivery, electronic libraries, virtual libraries, information support to independent networked learning - and those things only within the existing technology?

The real answer to the problems that librarians and information managers face is not narrowly-focused, competency-based, part-time training, but effective, fulltime professional education. The aim of that education is to produce people who question what is done now, who are capable of analysing situations and phenomena so as to identify novel solutions to problems, who have a perception of the value of information and literature that goes beyond the narrow, costrelated values of a right-wing ideology, who are capable of working in and with teams, and capable of leading new developments, and who have a full-awareness of the limits and potentials not only of information technology, but also of people, and of different ways of engaging with people and problems. Education may not always achieve its goals for every individual, but with that ethic it is capable of enabling people to realise their full potential for their own purposes.

Training for now is training for redundancy. Education is for the future.

Note: this short paper represents my personal views as a member of the Library Association. It should not be taken as representing the views of the University of Sheffield, nor of the Department of Information Studies in that University, nor of the Heads of Departments and Schools Committee of BAILER, which I chair. 